\title{
Thermal Analysis of Shell and Tube Type Heat Exchanger using Hybrid Nanofluid
}

\author{
Atul Bhattad* and S. Sudhakar Babu \\ Department of Mechanical Engineering, Koneru Lakshmaiah Educational Foundation, \\ Green Fields, Vaddeswaram 522502, India
}

('Corresponding author's e-mail: atul45007@gmail.com)

Received: 4 October 2020, Revised: 11 May 2021, Accepted: 30 May 2021

\begin{abstract}
A numerical analysis has been performed on a parallel flow shell and tube heat exchanger with different hybrid nanofluids in the present study. The heat exchanger consists of baffles which may increase the heat transfer characteristics. Hybrid nanofluids are used as a cooling medium. The author studied the effect of dissolved nanoparticles on Prandtl number and thermal transfer characteristics. The results show a convincing enhancement in the heat transfer characteristics by introducing hybrid nanoparticles into the primary fluid (water). The total concentration of nanoparticles was 2 vol\%. Different combinations of nanoparticles as a coolant studied were $\mathrm{Al}_{2} \mathrm{O}_{3}+\mathrm{MWCNT}, \mathrm{Al}_{2} \mathrm{O}_{3}+\mathrm{Beo}$, $\mathrm{Al}_{2} \mathrm{O}_{3}+\mathrm{AlN}$, and $\mathrm{Al}_{2} \mathrm{O}_{3}+\mathrm{TiO}_{2}$ (in equal volume ratios). The heat transfer rate was enhanced maximum by $16.5 \%$ for $\mathrm{Al}_{2} \mathrm{O}_{3}+\mathrm{MWCNT} /$ water hybrid nanofluid. Moreover, Prandtl number was observed reduced using nanoparticles with a maximum reduction of $10.5 \%$ for $\mathrm{Al}_{2} \mathrm{O}_{3}+\mathrm{TiO}_{2} /$ water hybrid nanofluid.
\end{abstract}

Keywords: Hybrid nanofluid, Heat transfer, Thermophysical properties, Numerical, Alumina
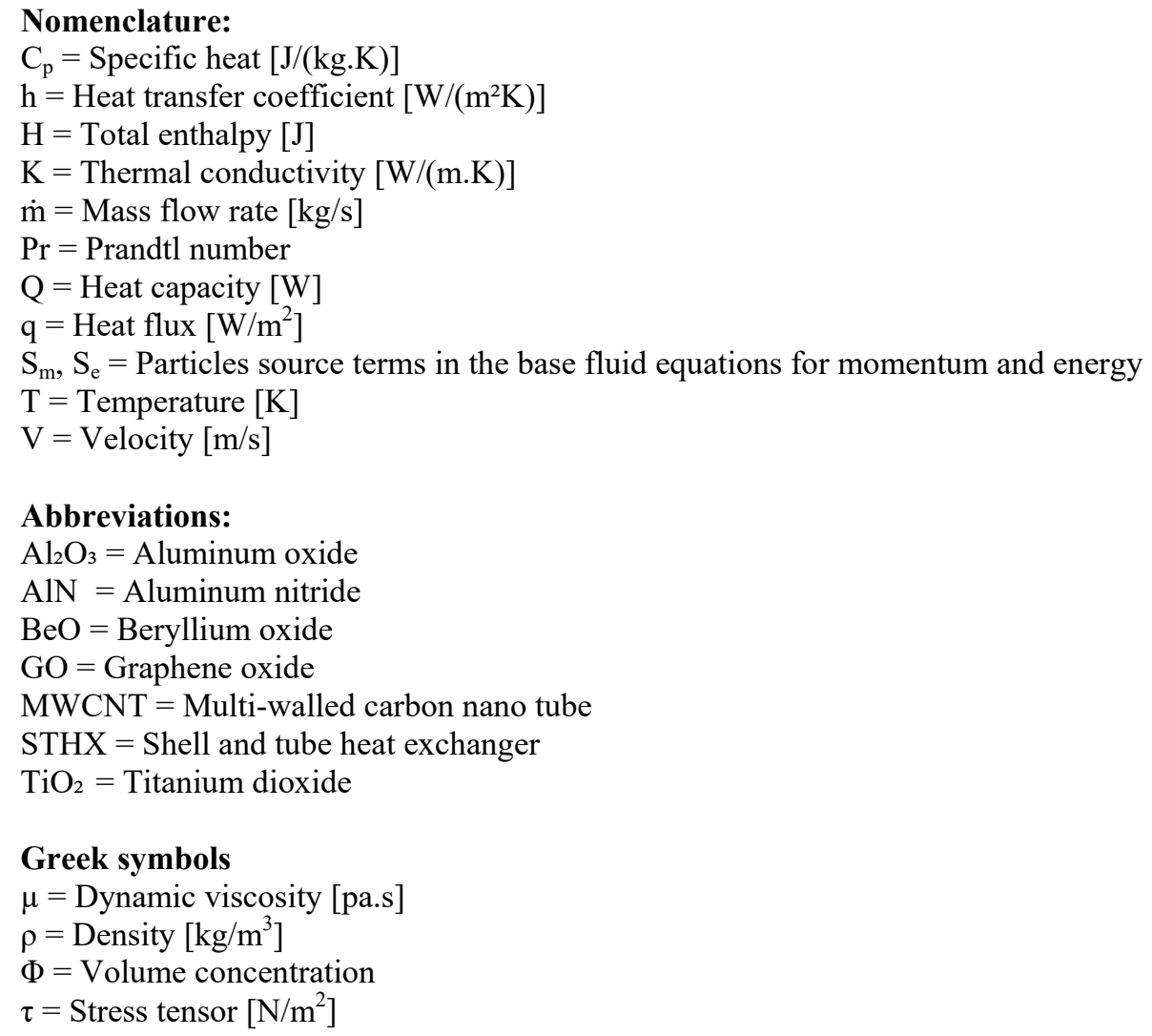


\author{
Subscript \\ $1=$ Particle 1 \\ $2=$ Particle 2 \\ Avg $=$ Average \\ bf $=$ Base fluid \\ $\mathrm{C}=$ cold \\ $\mathrm{h}=\mathrm{Hot}$ \\ hnf $=$ Hybrid nanofluid \\ $\mathrm{i}=$ Inlet \\ $\mathrm{O}=$ Outlet \\ $\mathrm{p}=$ particle
}

\title{
Introduction
}

In the last few decades, shell and tube exchangers (STHX) have been frequently used in engineering disciplines, such as chemical engineering, electricity generation, petrochemical, refrigeration, heating systems, food processing, etc. These heat exchangers are reasonably easy to produce and have a multipurpose application capability compared to other heat exchangers. Now, heat exchangers are commonly used in industrial applications as an integral feature of all thermal systems. These exchangers are typically prepared from hollow tubes with high design versatility and can be reformed without trouble by altering tube diameter, length, and configuration. Shell and tube exchangers can be built for high pressure based on the setting and high-pressure variations among fluids.

Studies on the nanofluid have been augmented very speedily over the past decade. In the advancement of nanofluid science, researchers have also recently tried to use hybrid nanofluid, which is planned by suspending dissimilar nanoparticles either in a mixture form or in a composite structure. In 1995, Choi and Eastman [1] was the first to use the concept of nanotechnology. He found significant augmentation in the nanofluid thermal conductivity as compared to base fluids. Nowadays, studies and work on nanotechnology have drawn considerable researchers' attention. Nanofluid is one of the core components of nanotechnology. Maxwell [2] demonstrated that a solid-liquid mixture could increase thermal conductivity by raising the volume fraction of solid particles. Large particles cause other problems in the base fluid, such as sedimentation. Thus, a new fluid category has been innovated as nanofluid to enhance the suspension thermal conductivity and stability. The influence of nanoparticles on the fluid thermophysical properties and their impact on heat transfer and pressure has made attention to the study of hybrid nanofluids.

The most basic hybrid nanofluid exclusivity concerns the composition in the base fluid of the 2 different dispersed nanoparticles. Therefore, if particle materials are chosen correctly, they will boost each other's positive characteristics and offset the other substance drawbacks. Aluminum (that is, ceramic) has many valuable properties, including chemical inertness and outstanding durability. An experimental study to synthesize the $\mathrm{Al}_{2} \mathrm{O}_{3}-\mathrm{Cu} /$ water hybrid nanofluid was conducted by Suresh et al. [3]. Salem [4] and Fares et al. [5] utilized MWCNT/ water and Graphene/ water nanofluids, respectively, to perform an experimental investigation on STHX to enhance thermal characteristics. Hojjat [6] developed an ANN model to optimize the influence of nanofluid as a coolant on shell and tube heat exchangers. Bahiraei et al. [7] performed a numerical investigation to study the hydrothermal characteristics of shell and tube heat exchangers using nanofluid and baffles.

Takabi and Salehi [8] numerically explore natural convection for $\mathrm{Al}_{2} \mathrm{O}_{3} /$ water nanofluid and $\mathrm{Al}_{2} \mathrm{O}_{3}$ $\mathrm{Cu} /$ water hybrid nanoparticles. Ponangi et al. [9] used graphene-based hybrid nanofluid in a compact heat exchanger to observe fluid effectiveness and pressure drop. Aghabozorg et al. [10] employed $\mathrm{Fe}_{2} \mathrm{O}_{3}$ CNT magnetic nanoparticles in a shell and tube heat exchanger under three specific temperatures. Sarkar et al. [11] presented research regarding the hybrid nanofluid synthesis, pressure drop, heat transfer, challenges, and applications. Somasekhar et al. [12] revealed particle concentration impact on Peclet number and the thermal transfer characteristics. Pahamli et al. [13] portrayed the contemporary addition of nanoparticles, and the increasing angle of inclination exposes that the thermal conductivity improves. Bhattad et al. [14] outlined the preparation, characterization, and properties of nanofluids. Singh and Sarkar [15] carried out exergy, energy, and economic assessments of $580 \mathrm{MW}$ shell and tube heat exchangers of nuclear power plants using various water-based hybrid nanofluids. Aparana et al. [16] prepared hybrid nanofluids to achieve a better rate of heat transfer relative to nanofluids dispersed with either of the dispersed fluids. Huminic and Huminic [17] discuss the thermo-physical properties 
(viscosity, density, thermal conductivity, and similar heats) and the heat transfer and fluid flow characteristics of fluid with hybrid nanoparticles. Xian et al. [18] aimed at determining a new hybrid nanofluid in the automotive cooling system. Bhattad and Sarkar [19] and Bhattad [20] shown the benefit of using Graphene hybrid nanofluid. Taherialekouhi et al. [21] examined the thermal conductivity of the hydro-graphene oxide (GO) nanostructure/aluminum oxide $\left(\mathrm{Al}_{2} \mathrm{O}_{3}\right)$ hybrid nanoparticles with a temperature range of $25-50^{\circ} \mathrm{C}$ and a volume fraction of $0.1,0.25,0.5,0.75$ and $1 \%$. Palanisamy and Kumar [22] reported the pressure difference and heat transfer of the helically coiled tube heat exchanger using MWCNT (Multi-wall carbon nanotube)/water nanofluids. Yang et al. [23] shown that various parameters like nanoparticle size, aspect ratio, base-fluid, volume fraction, temperature affect the nanofluid thermal conductivity. Moradi et al. [24] reviewed an empirical analysis of the results of nanoparticle concentration and temperature on thermal conductivity of TiO-MWCNTs / EG-water hybrid nanofluid. Sahu and Sarkar [25] have shown that particle shape significantly impacts the hybrid nanofluids efficiency in the natural circulation loop. Sharma et al. [26] produced hybrid nano-cutting fluid by mixing aluminum-based cutting fluid with multi-walled carbon nanotube (MWCNT) nanoparticles at various volumetric concentrations. Shahsavar et al. [27] assessed the hydrothermal and irreversible action of the water-Ag nanofluid in a modern heat sink with the spiral microchannels. Kumar and Sarkar [28] aimed at the hydrothermal activity of hybrid nanofluid by adjusting their ratio. Bhardwaj and Babu [29] used twisted tape to enhance the performance of STHX using nanofluid. Hagadishwar and Babu [30] used mixture of brine solution and nanoparticle in STHX for automotive radiator application.

The above survey indicates that no numerical studies have been performed on STHX using hybrid nanofluids as coolant and baffles. Also, a few research is available on the influence of hybrid nanofluid as a coolant in the shell and tube heat exchanger. Hence, an attempt has been made to numerically analyze the thermal performance of shell and tube heat exchanger with hybrid nanofluid as coolant. The various water-based hybrid nanofluids $\left(\mathrm{Al}_{2} \mathrm{O}_{3}+\mathrm{MWCNT} /\right.$ water, $\mathrm{Al}_{2} \mathrm{O}_{3}+\mathrm{Beo} /$ water, $\mathrm{Al}_{2} \mathrm{O}_{3}+\mathrm{AlN} /$ water, and $\mathrm{Al}_{2} \mathrm{O}_{3}+\mathrm{TiO}_{2} /$ water) were analyzed as coolant. Alumina nanoparticle is considered as the main particle because of easy availability and cheaper rate. A homogeneous model has been used for the numerical analysis purpose considering hybrid nanofluid in the homogeneous phase. The influence of nanoparticle volume concentration on the Prandtl number and heat transfer characteristics has been studied. The volume concentration chosen for the study purpose was 2 volume \%. Temperature contour and temperature distribution along the heat exchanger have been presented.

\section{Mathematical modeling and simulation}

A shell and tube heat exchanger has been considered for the performance evaluation of hybrid nanofluids in the present analysis. The author used 4 different water-based hybrid nanofluids $\left(\mathrm{Al}_{2} \mathrm{O}_{3}+\mathrm{MWCNT}, \mathrm{Al}_{2} \mathrm{O}_{3}+\mathrm{BeO}, \mathrm{Al}_{2} \mathrm{O}_{3}+\mathrm{AlN}\right.$, and $\mathrm{Al}_{2} \mathrm{O}_{3}+\mathrm{TiO}_{2}$ with a $50 / 50$ ratio) at total volume concentrations ( $2 \%$ ) for investigation along with base fluid (water). Table 1 displays the thermo-physical properties of various nanoparticles and the base fluid taken from the literature available. The configuration for STHX is shown in Figure 1. The steam flows in the shell of the heat exchanger, and the coolant flows in the tube side. 


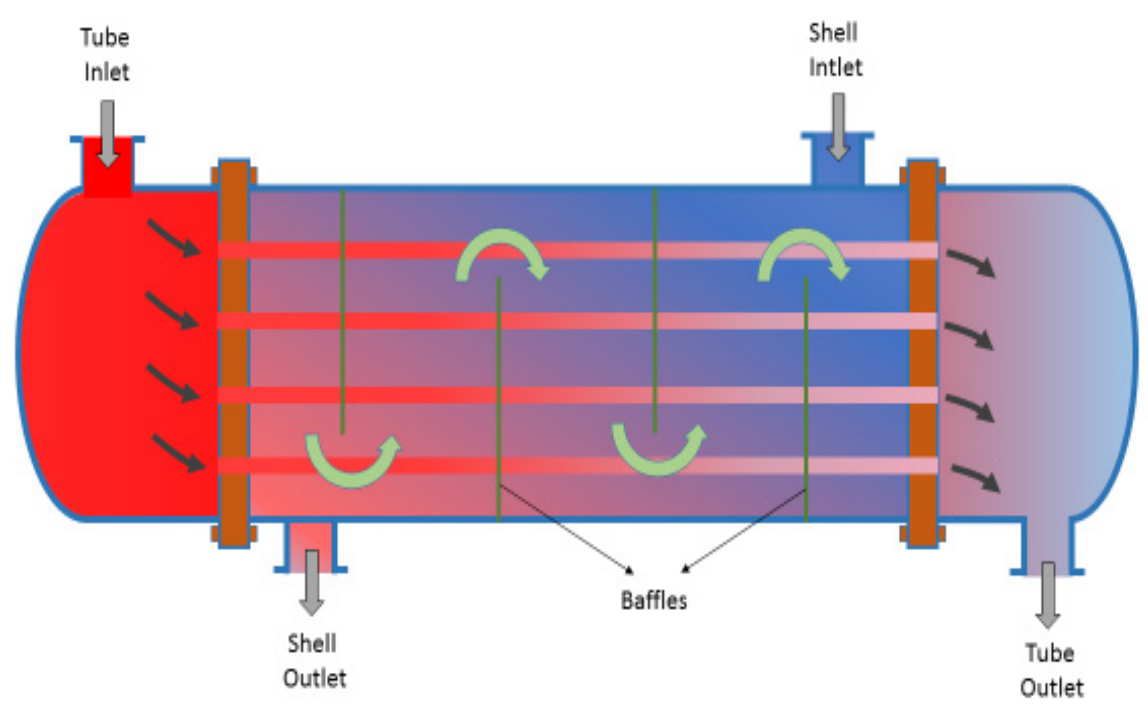

Figure 1 Shell and tube heat exchanger.

Table 1 Thermo-physical properties of base fluid and nanoparticles.

\begin{tabular}{|c|c|c|c|c|}
\hline Material & $\begin{array}{c}\text { Density, } \rho \\
\left(\mathrm{kg} / \mathrm{m}^{3}\right)\end{array}$ & $\begin{array}{l}\text { Sp.heat, } c_{p} \\
(\mathrm{~J} / \mathbf{k g ~ k})\end{array}$ & $\begin{array}{l}\text { Thermal conductivity, } k \\
(\mathbf{w} / \mathbf{m} . \mathrm{K})\end{array}$ & $\begin{array}{c}\text { Dynamic viscosity, } \mu \\
\left(\mathbf{N s} / \mathbf{m}^{2}\right)\end{array}$ \\
\hline Water & 995 & 4183 & 0.606 & 0.00076 \\
\hline $\mathrm{Al}_{2} \mathrm{O}_{3}$ & 3900 & 880 & 40 & - \\
\hline $\mathrm{BeO}$ & 3025 & 1046 & 285 & - \\
\hline AlN & 3260 & 732 & 180 & - \\
\hline MNCNT & 2600 & 740 & 3000 & - \\
\hline $\mathrm{TiO}_{2}$ & 4260 & 697 & 11.7 & - \\
\hline
\end{tabular}

For simulation, the following assumptions have been made;

1) Heat transfer happens only in the heat exchanger between steam and coolant; there is no heat contact with the surroundings.

2) Assuming nanoparticle to be spherical.

3) Assuming that hybrid nanofluid is of homogeneous phase.

4) Heat transfer surface has been assumed to be free from fouling.

5) The ambient temperature has been taken as the intake temperature of the heat exchanger, i.e., $27^{\circ} \mathrm{C}$.

\section{Modelling of shell and tube heat exchanger}

The shell and tube heat exchanger consists of shell, tubes, and baffles. Baffles are generally used to increase the turbulence that in turn increases the heat transfer characteristics. A homogeneous model was used for the analysis purpose. The geometry has been designed and analyzed in the ANSYS. The meshing element used was hexahedral. The cumulative number of nodes decided after performing the grid test for the shell and tube heat exchanger is 48638 . The boundary conditions defined are Inlet temperature as 300 $\mathrm{K}$, Outlet pressure as $0 \mathrm{~Pa}$ gauge, and a no-slip boundary condition. Governing equations used were mainly continuity equation, momentum equation, and energy equation mentioned as below [30];

$$
\nabla(\rho \vec{V})=0
$$

$$
\nabla(\rho \vec{V} \vec{V})=-\nabla p+\nabla(\mu \nabla \vec{V})+S_{m}
$$




$$
\nabla(\rho \vec{V} H)=-\nabla q-\tau \nabla \vec{V}+S_{e}
$$

The heat removed from the hot water, $\mathrm{Q}_{\mathrm{h}}$, and the heat absorbed by the hybrid nanofluid, $\mathrm{Q}_{\mathrm{c}}$ are calculated by Eq. (4) using the measured temperature and mass-flow rate;
$Q_{h}=\dot{m}_{h} C_{p h}\left(T_{h i}-T_{h o}\right)$
and
$Q_{c}=\dot{m}_{n f} C_{p n f}\left(T_{c o}-T_{c i}\right)$

(4)

The average heat transfer rate is defined as follows;

$Q_{\text {avg }}=\left(Q_{h}+Q_{c}\right) / 2$

(5)

Specifications of shell and tube heat exchanger

A single-pass shell and tube heat exchanger has been selected for analysis purpose. The specifications of the shell and tube are provided in Table 2.

Table 2 Specifications of shell and tube heat exchanger.

\begin{tabular}{cccc}
\hline Specifications of shell & \multicolumn{3}{c}{ Specifications of tube } \\
\hline Material & Stainless steel & Material & Stainless steel \\
\hline Inner diameter & $210 \mathrm{~mm}$ & Inner diameter & $18 \mathrm{~mm}$ \\
Outer diameter & $220 \mathrm{~mm}$ & Outer diameter & $20 \mathrm{~mm}$ \\
Baffles & 4 & Tubes & 7 \\
\hline
\end{tabular}

Hybrid nanofluid Thermophysical properties

Hybrid nanofluid density was obtained by [11];

$\rho_{\text {hnf }}=\emptyset_{p 1} \rho_{p 1}+\emptyset_{p 2} \rho_{p 2}+(1-\emptyset) \rho_{b f}$

where $\varnothing$ is the total volume concentration of 2 specific types of nanoparticles $\left(\mathrm{p}_{1}\right.$ and $\left.\mathrm{p}_{2}\right)$ distributed in hybrid nanofluid and measured as;

$\emptyset=\emptyset_{p 1}+\emptyset_{p 2}$

Hybrid nanofluid heat capacity can be ascertained as follows [11];

$c_{p h n f}=\frac{\emptyset_{p 1} \rho_{p 1} c_{p p 1}+\emptyset_{p 2} \rho_{p 2} c_{p p 2}+(1-\varnothing) \rho_{b f} c_{p b f}}{\rho_{h n f}}$

The most crucial property is thermal conductivity, which is responsible for enhanced heat transfer. Takabi and Salehi [8] suggested a new model for the thermal conductivity of hybrid nanofluids in this analysis. 


$$
\frac{k_{h n f}}{k_{b f}}=\frac{\frac{\emptyset_{p 1} k_{p 1}+\emptyset_{p 2} k_{p 2}}{\emptyset}+2 k_{b f}+2\left(\varnothing_{p 1} k_{p 1}+\emptyset_{p 2} k_{p 2}\right)-2 \emptyset k_{b f}}{\frac{\emptyset_{p 1} k_{p 1}+\emptyset_{p 2} k_{p 2}}{\varnothing}+2 k_{b f}-\left(\varnothing_{p 1} k_{p 1}+\emptyset_{p 2} k_{p 2}\right)+\emptyset k_{b f}}
$$

The nanofluid viscosity was calculated by a relationship suggested by Esfe et al. [31];

$$
\mu_{h n f}=\mu_{b f}\left(1+32.795 \emptyset-7214 \emptyset^{2}+714600 \emptyset^{3}-0.1941 * 10^{8} \emptyset^{4}\right)
$$

\section{Results and discussion}

The operating conditions like the steam side and coolant inlet temperature, and appropriate flow rate of fluid has been provided. The current study evaluates the heat transfer rate, temperature distribution, and Prandtl number using hybrid nanofluid as a coolant. A variation of $7.4 \%$ was found for the heat transfer rate with the experimental result, which is justifiable. The temperature distribution of the shell and tube heat exchanger has been shown in Figure 2.

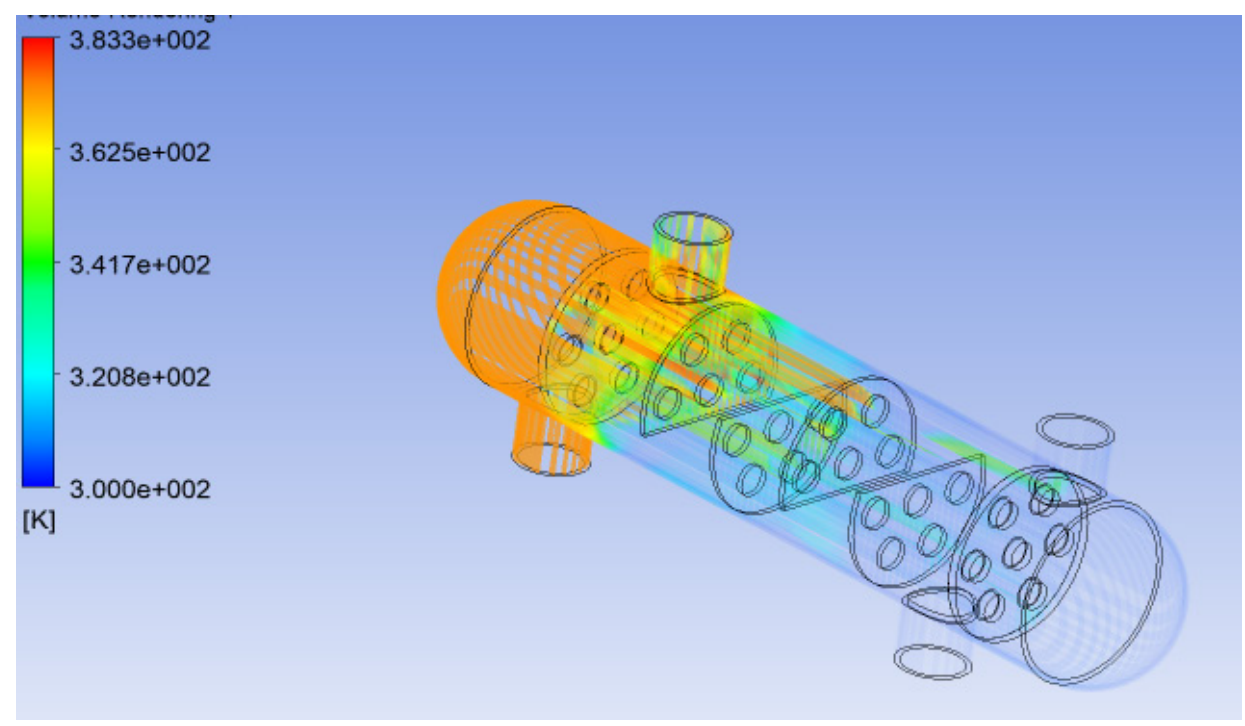

Figure 2 Temperature distribution along shell and tube heat exchanger.

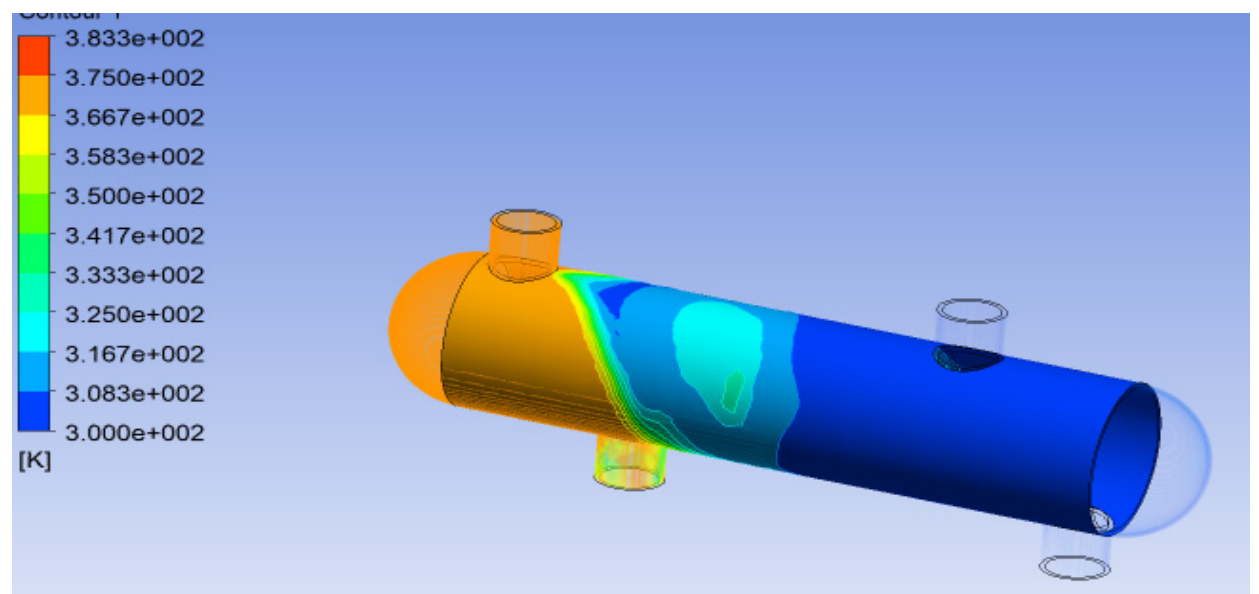

Figure 3 Temperature contour of shell and tube heat exchanger. 


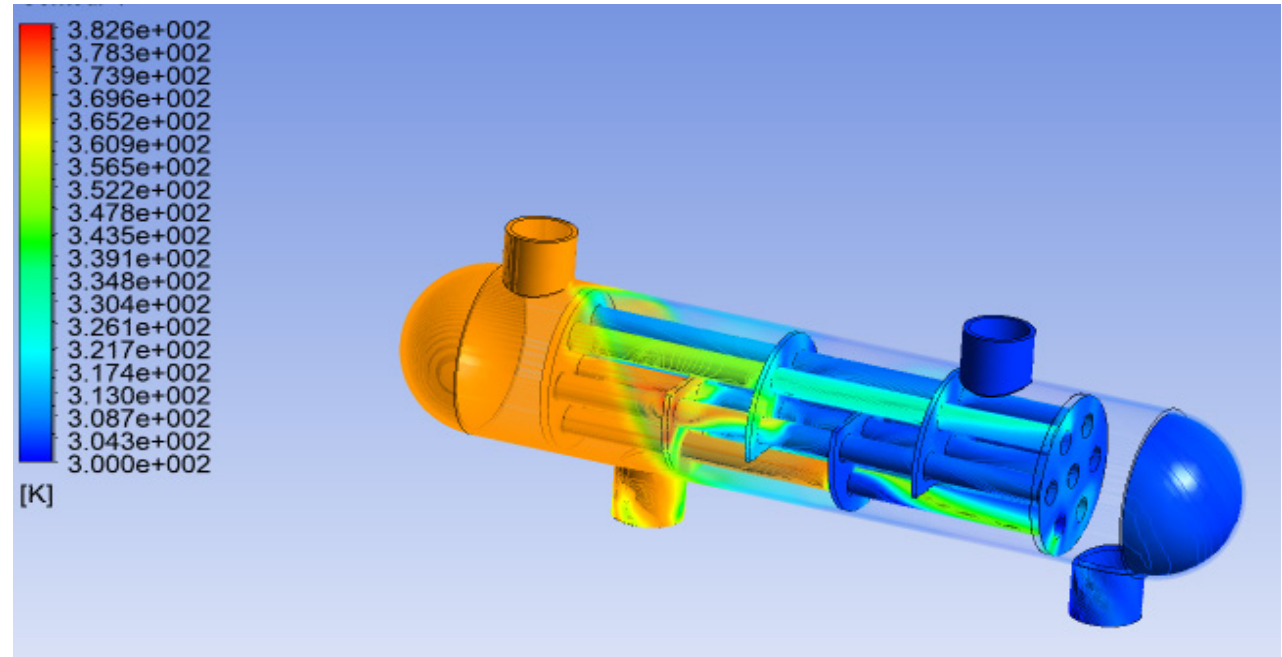

Figure 4 Thermal analysis of shell and tube heat exchanger.

Temperature contour and thermal analysis on the shell side and tube side of the shell and tube heat exchanger have been shown in Figures 3 and 4, respectively. The hot fluid on the side of the shell loses heat to the cold fluid as it flows through the length of the shell. Cold liquid on the tube side receives heat from the hot fluid as it flows through the length of the tube. Due to the presence of baffles, turbulence is increased that enhances heat transfer characteristics like temperature and heat transfer rate. The presence of nanoparticles is also one of the reasons for the enhancement of the heat transfer rate.

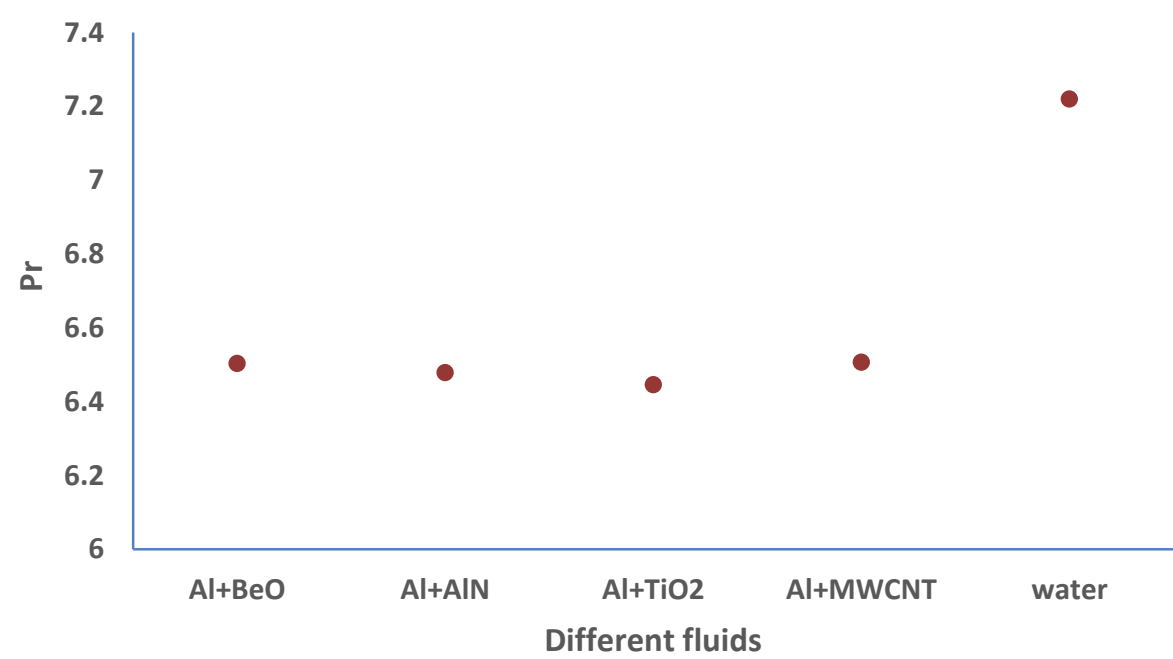

Figure 5 Prandtl number of different fluids.

Prandtl number is a dimensionless number, defined as the ratio between momentum and thermal diffusivity. It is often used in heat transfer and convection calculations. The above Figure 5 shows the Prandtl number of different fluids (Base fluid and hybrid nanofluids). Prandtl number was observed reduced using nanoparticles with a reduction of $10.5 \%$ for $\mathrm{Al}_{2} \mathrm{O}_{3}+\mathrm{TiO}_{2} /$ water hybrid nanofluid. This can be due to thermo-physical properties, mainly thermal conductivity and viscosity, as the Prandtl number comprises 3 thermo-physical properties. 


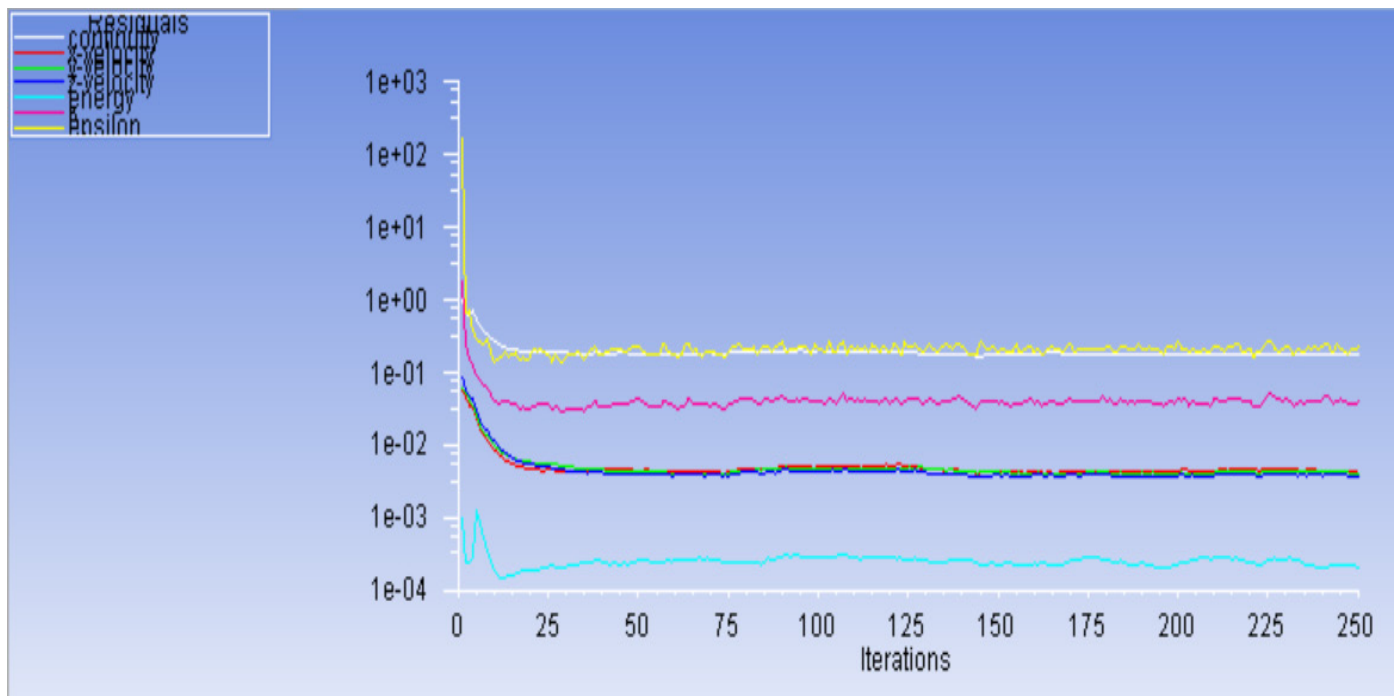

Figure 6 Iterations of hybrid nanofluids.

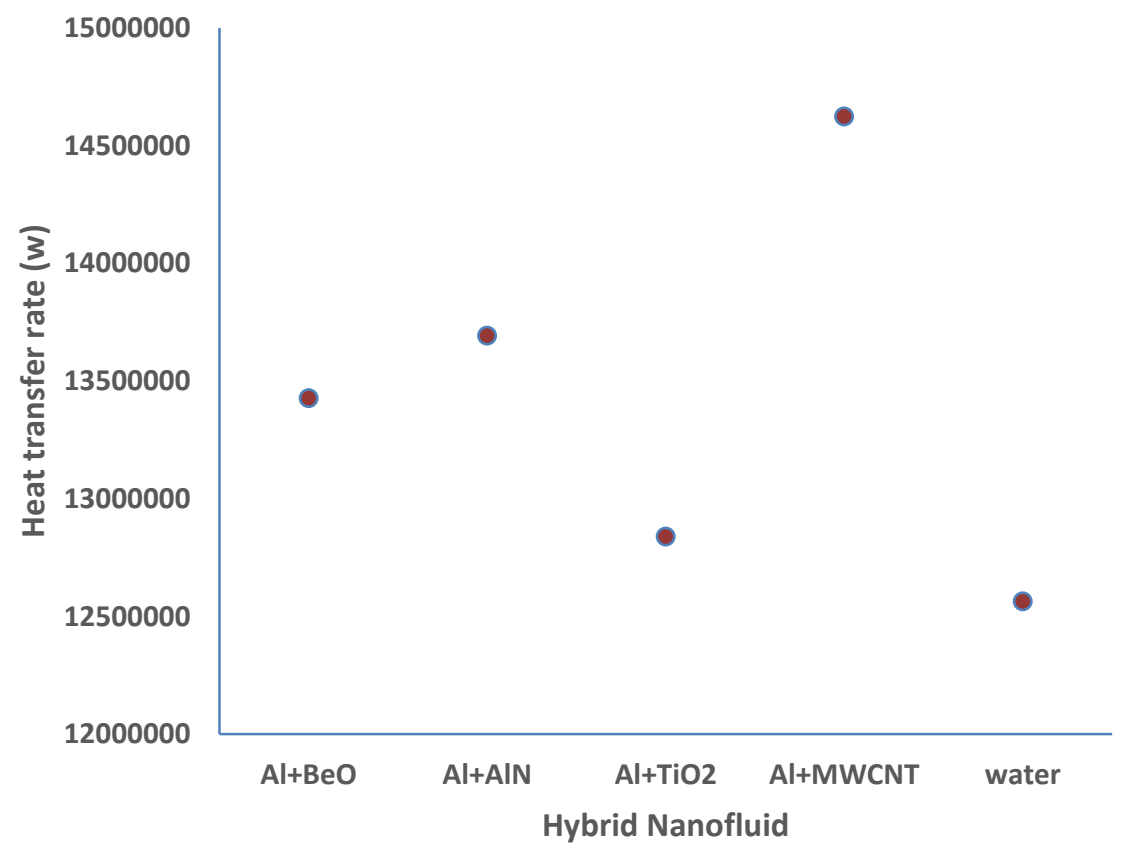

Figure 7 Heat transfer rate of hybrid nanofluids.

In Figure 6, the number of iterations required to achieve the targeted values for convergence of mass, momentum, and energy equations has been shown. In Figure 7, the heat transfer rate of different hybrid nanofluids is seen. Al+MWCNT has the highest heat transfer rate, and water has the lowest heat transfer rate. The maximum enhancement in the heat transfer rate has been observed around $16.5 \%$ for $\mathrm{Al}_{2} \mathrm{O}_{3}+\mathrm{MWCNT} /$ water hybrid nanofluid. The reason is the highest thermal conductivity and heat transfer coefficient of MWCNT nanoparticles compared to other studied nanoparticles. Al + MWCNT, Al + AlN, and $\mathrm{Al}+\mathrm{BeO}$ hybrid nanofluids are suggested as a better replacement to coolant for shell and tube heat exchanger application. They can be used in power plants to enhance the performance of thermal systems.

However, there are certain limitations in this study, like assumptions made during the numerical analysis. In the real experimental world, things may be a little different. There will be heat loss, friction loss, and more pressure drop. Particle nature and shape may differ as MWCNT is primarily cylindrical, while other studied particles are spherical. Hence, the inclusion of the shape factor is needed. In the 
present study, the author assumed that hybrid nanofluids are homogeneous and used a homogeneous model for analysis. But discrete phase model or mixture model might provide a better solution. Although heat transfer characteristics wise, the use of nanoparticles may be helpful, but they are not economical in greater volume in the present scenario. So, some method is needed to produce nanoparticles at a cheaper rate with more stability. Also, chemical reactions are required to study to find hydrophobic and hydrophilic nature. The above listed are some limitations/ disadvantages which lead the path for future scope.

\section{Conclusions}

Hybrid nanofluids are a relatively new stack of fluids for which more survey is required before practical applications in the industry. They may be used in almost all heat transfer applications due to the synergistic effect by which they provide desirable features for all of their components. They can be used as better coolant in many of the thermal applications like condenser, radiator etc. The points observed are mentioned below;

1) The current study shows that hybrid nanofluids contain a significant increase in thermal conductivity.

2) The maximum enhancement in the heat transfer rate was observed around $16.5 \%$ for $\mathrm{Al}_{2} \mathrm{O}_{3}+\mathrm{MWCNT} /$ water hybrid nanofluid than other fluids studied.

3) Moreover, the Prandtl number was observed reduced using nanoparticles with a maximum reduction of $10.5 \%$ for $\mathrm{Al}_{2} \mathrm{O}_{3}+\mathrm{TiO}_{2} /$ water hybrid nanofluid.

However, long-term reliability, the processing cycle, the development of suitable nanomaterial combinations to achieve synergistic impact, and the expense of nanofluids can be significant challenges behind practical applications. Therefore, considerable work is still required to recognize and address other challenges for specific applications.

\section{References}

[1] SUS Choi and JA Eastman. Enhancing thermal conductivity of fluids with nanoparticles. In: Proceedings of the ASME International Mechanical Engineering Congress \& Exposition, San Francisco, CA. 1995, p. 99-105.

[2] JC Maxwell. A treastise on electricity and magnetism. $2^{\text {nd }}$ ed. Oxford University Press, Cambridge, 1881.

[3] S Suresh, KP Venkitaraj, P Selvakumar and V Chandrasekar. Synthesis of $\mathrm{Al}_{2} \mathrm{O}_{3}-\mathrm{Cu} /$ water hybrid nanofluids using the two step method and its thermophysical properties. Colloid. Surface. Physicochem. Eng. Aspect. 2011; 388, 41-8.

[4] MR Salem. Experimental investigation on the hydrothermal attributes of MWCNT/water nanofluid in the shell-side of shell and semi-circular tubes heat exchanger. Appl. Therm. Eng. 2020; 176, 115438.

[5] M Fares, M AL-Mayyahi and M AL-Saad. Heat transfer analysis of a shell and tube heat exchanger operated with graphene nanofluids. Case Stud. Therm. Eng. 2020; 18, 100584.

[6] M Hojjat. Nanofluids as coolant in a shell and tube heat exchanger: ANN modeling and multiobjective optimization. Appl. Math. Comp. 2020; 365, 124710.

[7] M Bahiraei, M Naseri and A Monavari. A CFD study on thermohydraulic characteristics of a nanofluid in a shell-and-tube heat exchanger fitted with new unilateral ladder type helical baffles. Int. Commun. Heat Mass Trans. 2021; 124, 105248.

[8] B Takabi and S Salehi. Augmentation of heat transfer performance of the sinusoidal corrugated enclosure by employing hybrid nanofluid. Adv. Mech. Eng. 2014; 6, 147059.

[9] BR Ponangi, V Krishna and KN Seetharamu. Performance of compact heat exchanger in the presence of novel hybrid graphene nanofluids. Int. J. Therm. Sci. 2021; 165, 106925.

[10] MH Aghabozorg, A Rashidi and S Mohammadi. Experimental investigation of the heat transfer enhancement of $\mathrm{Fe}_{2} \mathrm{O}_{3}$-CNT/water magnetic nanofluids under a laminar, transient and turbulent flow inside the horizontal shell and tube heat exchanger. Exp. Therm. Fluid Sci. 2016; 72, 182-9.

[11] J Sarkar, P Ghosh and A Adil. A review on hybrid nanofluids: Recent research, development and applications. Renew. Sustain. Energ. Rev. 2015; 43, 164-77.

[12] K Somasekhar, KNDM Rao, V Sankararao, R Mohammed, M Veerendra and T Venkateswararao. A CFD Investigation of a heat transfer enhancement of shell and tube heat exchanger using $\mathrm{Al}_{2} \mathrm{O}_{3}$ water nanofluid. Mater. Today Proc. 2018; 5, 1057-62.

[13] Y Pahamli, MJ Hosseini, AA Ranjbar and R Bahrampoury. Effect of nanoparticle dispersion and 
inclination angle on melting of PCM in a shell and tube heat exchanger. J. Taiwan Inst. Chem. Eng. 2017; 81, 316-34.

[14] A Bhattad, J Sarkar and P Ghosh. Improving performance of refrigeration systems by using the nanofluids: A comprehensive review. Renew. Sustain. Energ. Rev. 2018; 82, 3656-69.

[15] SK Singh and J Sarkar. Energy, exergy and economic assessments of shell and tube heat exchanger using hybrid nanofluid as coolant. Int. Commun. Heat Mass Trans. 2018; 98, 41-8.

[16] Z Aparna, M Michael, SK Pabi and S Ghosh. Thermal conductivity of the aqueous $\mathrm{Al}_{2} \mathrm{O}_{3} / \mathrm{Ag}$ hybrid nanofluid at different temperatures and volume concentrations: An experimental development and investigation of new correlation function. Powder Tech. 2019; 343, 714-22.

[17] G Huminic and A Huminic. Hybrid nanofluids for the heat transfer applications - A state-of-the-art review. Int. J. Heat Mass Trans. 2018; 125, 82-103.

[18] HW Xian, N Azwadi, B Che and M Beriache. Heat transfer performance of the hybrid nanofluid as nanocoolant in automobile radiator system. J. Adv. Res. Des. 2018; 1, 14-25.

[19] A Bhattad and J Sarkar. Hydrothermal performance of plate heat exchanger with an alumina graphene hybrid nanofluid: Experimental study. J. Braz. Soc. Mech. Sci. Phys. 2020; 42, 377.

[20] A Bhattad. Exergy analysis of plate heat exchanger with graphene alumina hybrid nanofluid: Experimentation. Int. J. Exerg. 2020; 33, 254-62.

[21] R Taherialekouhi, S Rasouli and A Khosravi. An experimental study on the stability and thermal conductivity of water-Graphene Oxide/Aluminum Oxide as a cooling hybrid nanofluid. Int. J. Heat Mass Transf. 2019; 145, 118751.

[22] K Palanisamy and PCM Kumar. Experimental investigation on the convective heat transfer and pressure drop of cone helical coiled tube heat exchanger using the carbon nanotubes/water nanofluids. Heliyon 2019; 5, 01705.

[23] L Yang, W Ji, JN Huang and G Xu. An updated review on influential parameters on the thermal conductivity of nano-fluids. J. Mol. Liq. 2019; 296, 111780.

[24] A Moradi, M Zareh, M Afrand and M Khayat. Effects of volume concentration and temperature on thermal conductivity of $\mathrm{TiO}_{2}$-MWCNTs (70 - 30)/EG-Water hybrid nano-fluid. Powder Tech. 2020; 362, 578-85.

[25] M Sahu and J Sarkar. Steady-state energetic and exergetic performances of single-phase natural circulation loop with hybrid nanofluids. J. Heat Trans. 2019; 141, 082401.

[26] AS Kumar, AK Tiwari, AR Dixit and RK Singh. Measurement of machining forces and surface roughness in turning of AISI 304 steel using alumina-MWCNT hybrid nanoparticles enriched cutting fluid. Meas. J. Int. Meas. Confed. 2020; 150, 107078.

[27] A Shahsavar, MM Baseri, AAAA Al-Rashed and M Afrand. Numerical investigation of the forced convection heat transfer and the flow irreversibility in a novel heatsink with helical microchannels working with synthesized water-silver nanofluid. Int. Commun. Heat Mass Transf. 2019; 108, 104324.

[28] $\mathrm{V}$ Kumar and $\mathrm{J}$ Sarkar. Particle ratio optimization of $\mathrm{Al}_{2} \mathrm{O}_{3}-\mathrm{MWCNT}$ hybrid nanofluid in minichannel heat sink for best hydrothermal performance. Appl. Therm. Eng. 2020; 165, 114546.

[29] MPS Bharadwaj and SS Babu. Heat transfer enhancement in 2S-2T shell and tube heat exchanger with wire coil and twisted tape turbulators using $\mathrm{TiO}_{2}$ nanofluid. Int. J. Mech. 2017; 8, 846-59.

[30] V Bianco, F Chiacchio, O Manca and S Nardini. Numerical investigation of nanofluids forced convection in circular tubes. Appl. Therm. Eng. 2009; 29, 3632-42.

[31] K Jagadishwar and SS Babu. Performance investigation of water and propylene glycol mixture based nano-fluids on automotive radiator for enhancement of heat transfer. Int. J. Mech. 2017; 8, 822-33. 